\title{
Postpartum haemorrhage (PPH) rates in randomized trials of PPH prophylactic interventions and the effect of underlying participant PPH risk: a meta-analysis
}

\author{
Lydia Hawker ${ }^{*}$ (D) and Andrew Weeks
}

\begin{abstract}
Background: Postpartum haemorrhage (PPH) remains a leading cause of maternal mortality. Many trials assessing interventions to prevent PPH base their data on low risk women. It is important to consider the impact data collection methods may have on these results. This review aims to assess trials of PPH prophylaxis by grading trials according to the degree of risk status of the population enrolled in these trials and identify differences in the PPH rates of low risk and high risk populations.

Methods: Systematic review and meta-analysis using a random-effects model. Trials were identified through CENTRAL. Trials were assessed for eligibility then graded according to antenatal risk factors and method of birth into five grades. The main outcomes were overall trial rate of minor PPH (blood loss $\geq 500 \mathrm{ml}$ ) and major PPH (> $1000 \mathrm{ml}$ ) and method of determining blood loss (estimated/measured).

Results: There was no relationship between minor or major PPH rate and risk grade (Kruskal-Wallis: minor $-\mathrm{T}=0.92$, $p=0.82$; major $-\mathrm{T}=0.91, p=0.92$ ). There was no difference in minor or major $\mathrm{PPH}$ rates when comparing estimation or measurement methods (Mann-Whitney: minor $-U=67, p=0.75$; major $-U=35, p=0.72$ ). There was however a correlation between \% operative births and minor PPH rate, but not major PPH (Spearman $r=0.32 \mathrm{v}$. Spearman $r=0.098$ ).

Conclusions: Using data from trials using low risk women to generalise best practice guidelines might not be appropriate for all births, particularly complex births. Although complex births contribute disproportionately to PPH rates, this review showed they are often underrepresented in trials. Despite this, there was no difference in reported PPH rates between studies conducted in high and low risk groups. Method of birth was shown to be an important risk factor for minor PPH and may be a better predictor of PPH than antenatal risk factors. Women with operative births are often excluded from trials meaning a lack of data supporting interventions in these women. More focus on complex births is needed to ensure the evidence base is relevant to the target population.
\end{abstract}

Keywords: Postpartum haemorrhage, PPH risk, Population risk, PPH prophylaxis, PPH prevention

\footnotetext{
* Correspondence: l.a.hawker@liverpool.ac.uk

Sanyu Research Unit, Department of Women's and Children's Health,

University of Liverpool, Liverpool, UK
}

(c) The Author(s). 2020 Open Access This article is distributed under the terms of the Creative Commons Attribution 4.0 International License (http://creativecommons.org/licenses/by/4.0/), which permits unrestricted use, distribution, and reproduction in any medium, provided you give appropriate credit to the original author(s) and the source, provide a link to the Creative Commons license, and indicate if changes were made. The Creative Commons Public Domain Dedication waiver (http://creativecommons.org/publicdomain/zero/1.0/) applies to the data made available in this article, unless otherwise stated. 


\section{Background}

Postpartum haemorrhage (PPH) remains a leading obstetric emergency, causing $25 \%$ maternal deaths worldwide [1]. It is defined by the Royal College of Obstetricians and Gynaecologists (RCOG) as blood loss from the genital tract within the first $24 \mathrm{~h}$ after birth of at least $500 \mathrm{ml}$ (minor) and at least $1000 \mathrm{ml}$ (major) [2].

Causes of PPH are separated into the 4 'T's - tone, thrombin, trauma and tissue [2]. Common causes include uterine atony (tone), preeclampsia (thrombin), perineal laceration (trauma) and retained placenta (tissue). The RCOG recognize several risk factors for PPH (Table 1) [2], however, this is not an exhaustive list and associations have been found with other risk factors including foetal death, maternal age and history of bleeding during pregnancy (antepartum haemorrhage).

NICE currently recommend advising active over physiological management due to its lowered risk of severe PPH $(13 / 1000$ vs $29 / 1000)$ [3]. Active management includes the use of uterotonic drugs and controlled cord traction. For women who progress to $\mathrm{PPH}$, treatment involves further use of uterotonics, uterine massage, intravenous fluid, bladder emptying and controlled cord traction. Current evidence suggests the first line drug in this instance should be oxytocin, ergometrine or a combination of these [3].

Weeks and Nielson suggest that the evidence used to recommend treatment may not be relevant to many women who go on to suffer a PPH [4]. They suggest that the current evidence base is centred on uncomplicated births - with women at low risk of PPH - which only represents a small proportion of major PPH cases [5]. Those with more risk factors and complicated births may require a different approach in terms of treatment. Therefore, $\mathrm{PPH}$ research requires a global effort to refocus the efforts of $\mathrm{PPH}$ trials to access and improve the treatment for those in more at-risk groups.

Baseline variation in trial rates may be related to methods of blood loss measurement. Visual estimation is thought to be the preferred method as it is rapid and does not require practical equipment. However, comparison with objective methods has identified inaccuracies with visual estimation [6]. Hancock et al. performed a

Table 1 RCOG list of recognised risk factor for postpartum haemorrhage

\begin{tabular}{ll}
\hline Multiple pregnancy & Retained placenta \\
Previous postpartum haemorrhage & Perineal laceration \\
Pre-eclampsia & Episiotomy \\
Foetal macrosomia & General anaesthesia \\
Failure to progress (2nd stage) & $\begin{array}{l}\text { Elective or emergency } \\
\text { caesarean section }\end{array}$ \\
Prolonged third stage & \\
Placenta accrete & \\
\hline
\end{tabular}

systematic review of blood loss measurement which found that estimation of blood loss tended towards overestimation of smaller volumes but increasingly underestimated larger volumes [6]. It may be necessary to standardise measurement of blood loss postpartum for what is a 'crucial step' to ensure rapid treatment and a reduction in maternal mortality.

The aim of this current review is to assess PPH rates in trials of prophylactic interventions for $\mathrm{PPH}$, based on the PPH risk status of the trial populations. The rates between higher and lower risk trial populations will be compared. We will also consider the impact that blood loss assessment methods may have on these results.

\section{Methods}

The protocol for this review was registered with PROSPERO (CRD42018082322).

\section{Trials and interventions}

Randomised-controlled trials and cluster-randomised trials of intervention for the prevention of $\mathrm{PPH}$ were included in this study. Any intervention which acts to prevent PPH, administered in the third stage of labour, was included. The intervention could be pharmacological, examples include misoprostol, carbetocin, oxytocin, tranexamic acid and syntometrine, or non-pharmacological, including nipple stimulation, controlled cord traction and uterine massage. Interventions which related to the treatment or management of PPH were excluded as well as those interventions specifically related to the prevention, treatment and management of retained placenta.

\section{Identification of trials}

The search was conducted through the Cochrane Central Register of Controlled Trials (CENTRAL) using the following search strategy; 'randomised controlled trials' and 'third stage of labour or postpartum haemorrhage' and 'prophylactic or preventative or prophylaxis'. Published data from eligible trials was then included into further analysis. CENTRAL has a detailed search strategy which includes hand and electronic searches of PubMed, Embase, and ClinicalTrials.gov databases [7].

\section{Assessment and eligibility}

The PRISMA (Preferred Reporting Items for Systematic Reviews and Meta-Analysis) guidelines were used as the basis for assessment. Trials were assessed for eligibility against five criteria:

1. Trials are appropriately randomised - randomised controlled trial (RCT) or cluster-randomised only

2. Trials report on the accepted definition of minor and major PPH (RCOG guidelines), or the equivalent value in peripartum fall in haemoglobin. 
3. Trials identify their blood loss assessment method

4. Trials report the number of PPH cases in each arm

5. Trials report the baseline participant characteristics.

The definition used for $\mathrm{PPH}$ for this review is blood loss greater than or equal to $500 \mathrm{ml}$ (minor) or greater than $1000 \mathrm{ml}$ (major) [2]. An equivalent measurement for blood loss of $500 \mathrm{ml}$ and $1000 \mathrm{ml}$ is the drop of haemoglobin by $10 \%(10 \mathrm{~g} / \mathrm{l})$ or $20 \%(20 \mathrm{~g} / \mathrm{l})$ respectively. This assumes a rise in plasma volume during pregnancy giving a total blood volume at term of approximately 5000mls [8] and that a loss of $10 \%$ of this volume $(5000 \mathrm{mls})$ will also reduce the haemoglobin by this amount. Trials using this measurement and definition were also included.

\section{Risk of bias analysis}

The risk of bias for included trials was assessed using the criteria outlined within the Cochrane Handbook for Systematic Reviews of Intervention [7]. If possible, risk of bias assessments from previously published reviews were used and have been appropriately identified in the assessment tables. Where no previous risk of bias assessment was found, the risk of bias was assessed independently by LH and AW.

Assessments have been made as low, unclear or high risk using the following domains;

1. Random sequence generation (selection bias) randomisation methods were assessed to determine risk of bias.

2. Allocation concealment (selection bias) allocation concealment methods and the risk of advanced allocation knowledge were assessed.

3. Blinding of the participants and personnel (performance bias) - methods to blind both participants and personnel to the allocated trial arm were assessed.

4. Blinding of outcome assessment (detection bias) - methods used to blind the outcome assessors to the trial arm and the objectivity of outcomes were assessed.

5. Incomplete outcome data (attrition bias) missing outcome data and attrition rates were assessed.

6. Selective reporting (reporting bias) - where possible the published registration was assessed to determine selective reporting. Assessment was also made based on the expected reported outcomes for the trial.

7. Other bias - addressed on an individual trial basis where concerns over the risk of bias were identified.

\section{Data synthesis and outcomes}

Eligible trials were graded according to the antenatal risk factors included in their study population and the method of delivery, using an original grading system developed by the authors based on risk factors in the RCOG guidelines [2] (Table 2). Method of delivery was assessed as a percentage of operative births (operative vaginal or caesarean section). In relation to antenatal risk factors, studies were classed as low risk or unselected. Low risk studies were those which defined themselves as low risk, stated that women with postpartum risk factors were purposely excluded or excluded at least 4 of the following; multiple pregnancy, previous $\mathrm{PPH}$, preeclampsia, fibroids, polyhydramnios, intrauterine foetal demise, antepartum haemorrhage and placenta praevia/accreta (for caesarean section only).

The primary outcome was the average rate of $\mathrm{PPH}$ (minor and major) for each grade. As a secondary outcome, the method of calculating blood loss and determining PPH was also identified and analysed.

\section{Statistical analysis}

For each grade and severity of $\mathrm{PPH}$, a random effects pooled proportion (the number of women with $\mathrm{PPH}$ in relation to the whole trial population) with $95 \%$ confidence intervals (CI) was calculated using proportion meta-analysis. Statistical heterogeneity was assessed using the $I^{2}$ statistic where $>30 \%$ was considered low, > $50 \%$ considered medium and $>75 \%$ considered high heterogeneity, a $p$-value $<0.1$ was considered significant [7]. An overall pooled proportion across all grades for minor and major PPH was also generated and relationship between grade and pooled proportion was analysed using the Kruskal-Wallis test, where $p<0.05$ was considered significant. To compare blood loss estimation and measurement, the Mann-Whitney $U$ test was performed within each grade where appropriate, and for overall comparison of rates for minor and major PPH $(\alpha=0.05)$. Post-hoc analysis using Spearman Rank Correlation was also carried out to identify any significant correlation

Table 2 Grading system for trials of intervention for PPH prophylaxis, based on participant inclusion criteria

\begin{tabular}{ll}
\hline Grade & Definition \\
\hline 1 & Only includes data from low risk women antenatally who have normal vaginal births \\
3 & Includes data from women who are low risk antenatally and who have less than $10 \%$ operative births \\
4 & Includes women who are low risk antenatally but who have 10\% or more operative births \\
5 & Includes data from unselected antenatal women where all births are included irrespective of rate of operative birth \\
\hline
\end{tabular}


between the percentage of operative births and proportion of PPH across all included studies. A change from the registered protocol was the use of StatsDirect3 to carry out statistical analysis.

\section{Results}

\section{Search results}

The search through the Cochrane Reviews database identified 93 trials which should be screened and assessed for eligibility (Fig. 1). Of these 93 trials, 30 were eligible for inclusion for grading and meta-analysis.

There were 28 trials which reported results for the minor PPH outcome and 21 trials for major PPH. Assessment of blood loss was measured or calculated using $\mathrm{Hb}$ only in 22 trials and was estimated only in seven trials. One trial reported estimated blood loss $\geq 500 \mathrm{ml}$ (minor $\mathrm{PPH}$ ), and a measured $\mathrm{Hb}$ of $2 \mathrm{~g} / \mathrm{dL}$ (major PPH) [9].

Of the excluded trials, 50 were excluded during screening and a further 13 were excluded as they did not meet the review eligibility criteria.

\section{Risk of bias of included trials}

Risk of bias assessment summaries are shown in Figs. 2 and 3. Individual risk of bias assessments can be found in Additional file 1.

The risk of bias was assessed independently by $\mathrm{LH}$ and AW for 14 trials [10-23]. Six assessments [24-29] were produced during a review by Gallos et al. [30]. The risk of bias assessments for the Althabe 2009 [31] and DeneuxTharaux 2013 [32] trials were completed during a review by Hofmeyr, Mshweshwe and Gülmezoglu [33]. Oladapo, Okusanya and Abalos [34] completed a risk of bias assessment for the Dagdeviren 2016 [35] trial. The risk of bias for the Jackson 2001 [9] trial was completed during the review by Soltani, Hutchon and Poulose [36]. Westhoff, Cotter and Tolosa [37] carried out a risk of bias assessment for the Poeschmann 1991 [38] trial. Where appropriate, risk of bias assessments from multiple sources were used to produce a single risk of bias for the current review. Risk of bias assessments for the Stanton 2013 [39] trial were completed by Gallos et al. [30] and Pantja et al. [40]. The Rogers 1998

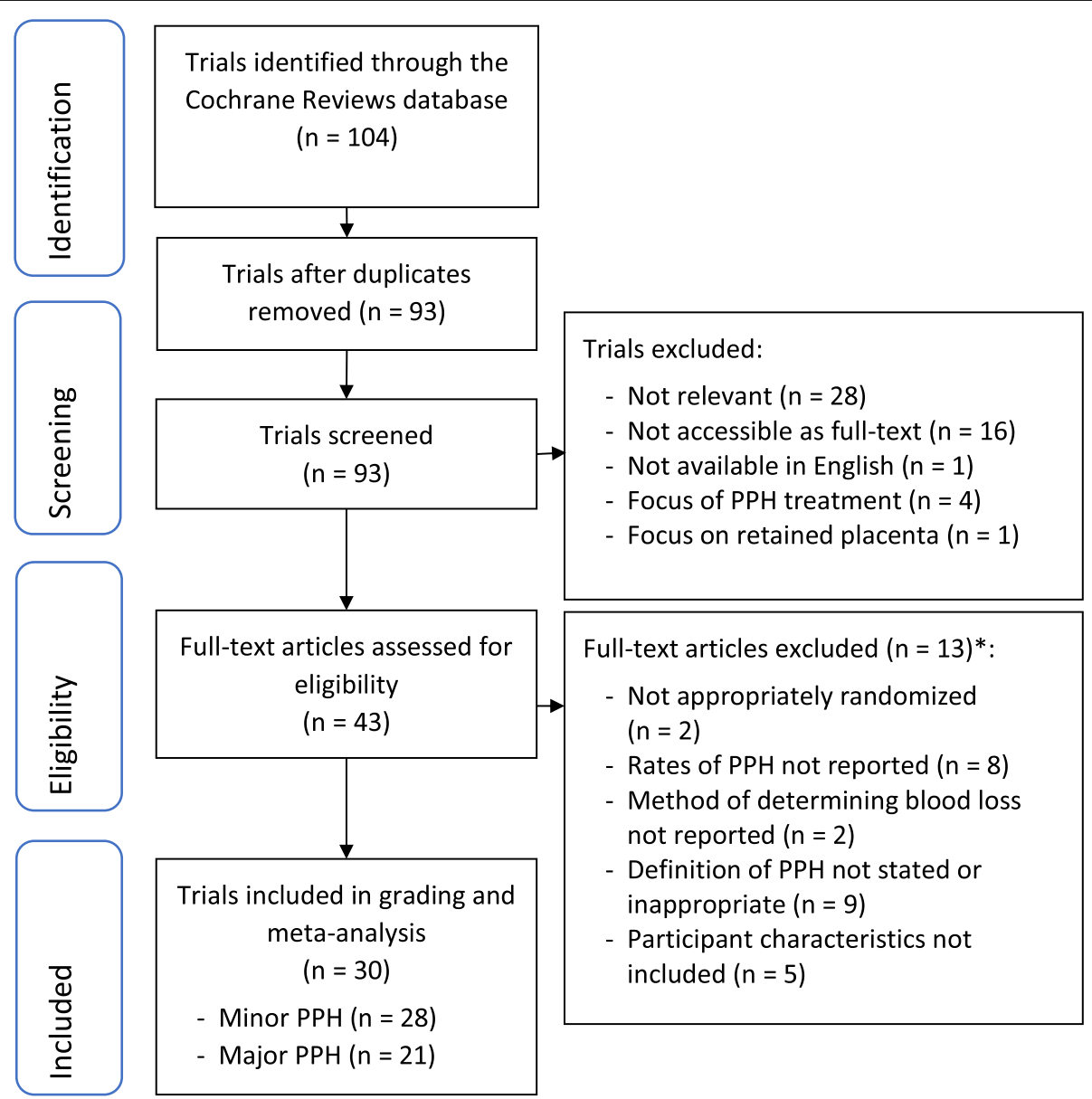

Fig. 1 PRISMA diagram for the selection and eligibility assessment of trials focussing on prophylactic postpartum haemorrhage interventions. * Some full-text articles were excluded for not meeting more than one inclusion criteria. PPH - postpartum haemorrhage; PRISMA - Preferred Reporting Items for Systematic Reviews and Meta-Analysis 


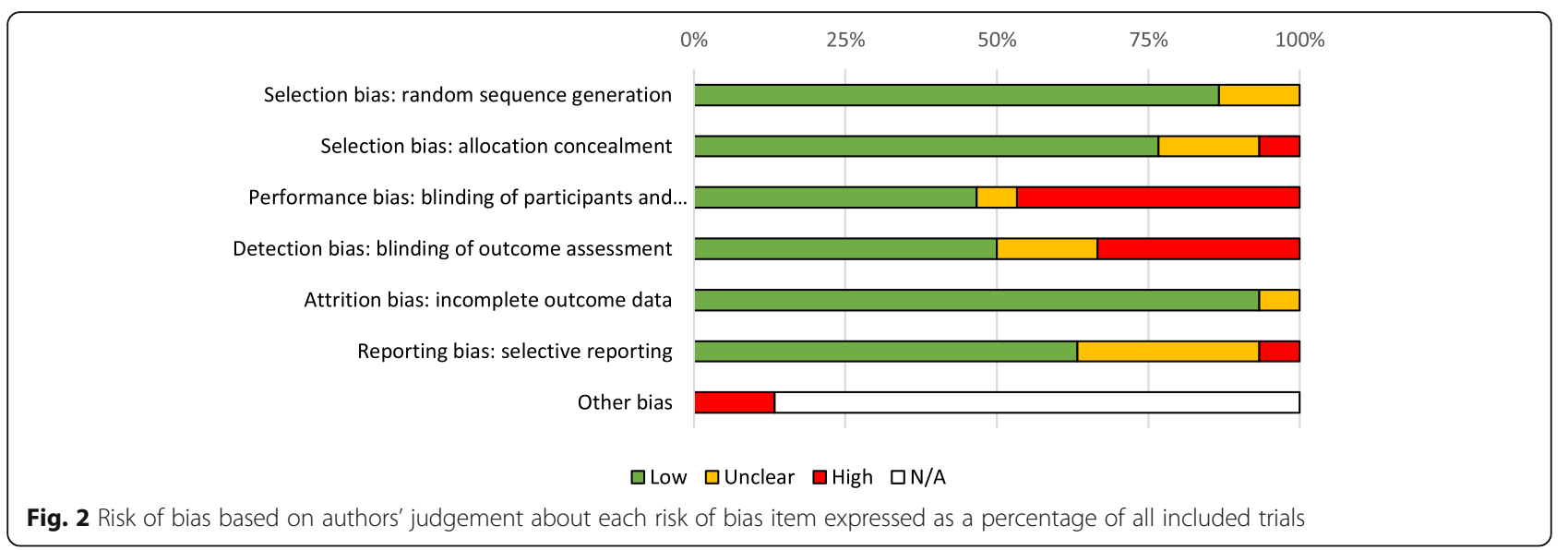

[41] and Prendiville 1988 [42] risk of bias assessments were completed by Begley et al. [43] and Gallos et al. [30]. The Groot 1996 [44] trial risk of bias was completed by Gallos et al. [30], Liabsuetrakul et al. [45] and Westhoff, Cotter and Tolosa [37]. The Attilakos 2010 [46] risk of bias was assessed by two previous reviews, Gallos et al. [30] and Su, Chong and Samuel [47].

Selection bias was judged to be low risk in $87 \%$ of trials for random sequence generation and for $77 \%$ of trials for allocation concealment. Four trials were considered to have an unclear risk of selection bias as the methods to describe adequate random sequence generation were not reported or inadequately described $[14,15,28,42]$. There was an unclear risk for five trials $[19,28,29,35,39]$ concerning allocation concealment as it was not reported appropriately. The Diop 2016 [11] and Raghavan 2015 [21] trials were cluster randomised trials meaning allocation would have been known in advance so were judged to be high risk for inadequate allocation concealment.

Performance bias was low risk in $47 \%$ of trials, unclear risk in $7 \%$ and high risk in $47 \%$. Detection bias showed similar results with $50 \%$ of trials deemed low risk, $17 \%$ unclear and 33\% high risk. The large number of trials judged to be unclear or high risk for performance and detection bias were commonly due to difficult blinding participants and personnel to interventions due to the differences in administration $[11,16,19,21,22,31,32,35,39,41,42$, $44]$, unclear reporting of methods [28, 29] and a likelihood that blinding could be broken $[18,20]$. The DeneuxTharaux 2013 [32] and Groot 1996 [44] trials were judged to be high risk of performance bias but low and unclear risk of detection bias, respectively, due to the use of objective measurements for the primary outcome.

Attrition bias was low risk in $93 \%$ of trials. The Orji 2008 [28] trial was considered to have an unclear risk of attrition bias as the authors did not report attrition or any incomplete data. The Diop 2016 [12] trial was also considered to have unclear risk as the attrition rates in the misoprostol and oxytocin arms, 27.5 and $22.5 \%$ respectively, were high but the authors stated that all women given an intervention were followed up and were included in the analysis. Reporting bias was low risk in 63\%, unclear in $30 \%$ and high risk in $7 \%$. For eight trials deemed to have unclear risk of reporting bias, the protocol was not published or could not be accessed [10, 18, 25, 27-29, 41, 42]. The Shady 2017 [22] trial was judged to have an unclear risk of reporting bias as the definition of $\mathrm{PPH}$ was unclear. The protocol for the Hofmeyr 2011 [13] trial stated the rates of transfusion and haemoglobin $<8 \mathrm{~g} / \mathrm{dl}$ after $24 \mathrm{~h}$ would be reported as secondary outcomes. However, this was not reported in the published trial results and was therefore judged to be high risk of selective reporting. The Lamont 2001 [15] trial did not report all expected outcomes such as additional surgery and transfusion rates so was also considered to be high risk.

Other bias was assessed on an individual basis and included a high risk of bias for early termination of the Poeschmann 1991 [38] and Rogers 1998 [41] trials. The Prendiville 1988 [42] trial was deemed to have a high risk of bias due to a smaller sample size and a protocol change after five months. The data of women included before the protocol change was still included within the final analysis. The Diop 2016 [11] trial changed the huts receiving the misoprostol or oxytocin intervention after initiation of the trial which has been considered to have a high risk of bias.

\section{Primary outcomes \\ Proportion analysis for minor PPH grades}

Overall, there were 28 trials reporting the proportion of women with a minor PPH. Grade 1 included 11 trials and had a random effects pooled proportion of $0.10(95 \% \mathrm{CI}=$ 0.042 to 0.18$)$, with high heterogeneity $\left(p<0.0001 ; I^{2}=\right.$ 99.1\%; $95 \% \mathrm{CI}=98.9$ to $99.2 \%$ ) (Additional file 2: Figure S1) $[12,13,17-19,21,22,26,28,38,44]$. Grade 2 included four trials and had a random effects pooled proportion of 0.15 (95\% CI $=0.067$ to 0.26$)$, with high heterogeneity $\left(p<0.0001 ; I^{2}\right.$ of $96.6 \% ; 95 \% \mathrm{CI}=94.6$ to 97.7\%) (Additional file 2: Figure S2) [16, 24, 35, 41]. Grade 


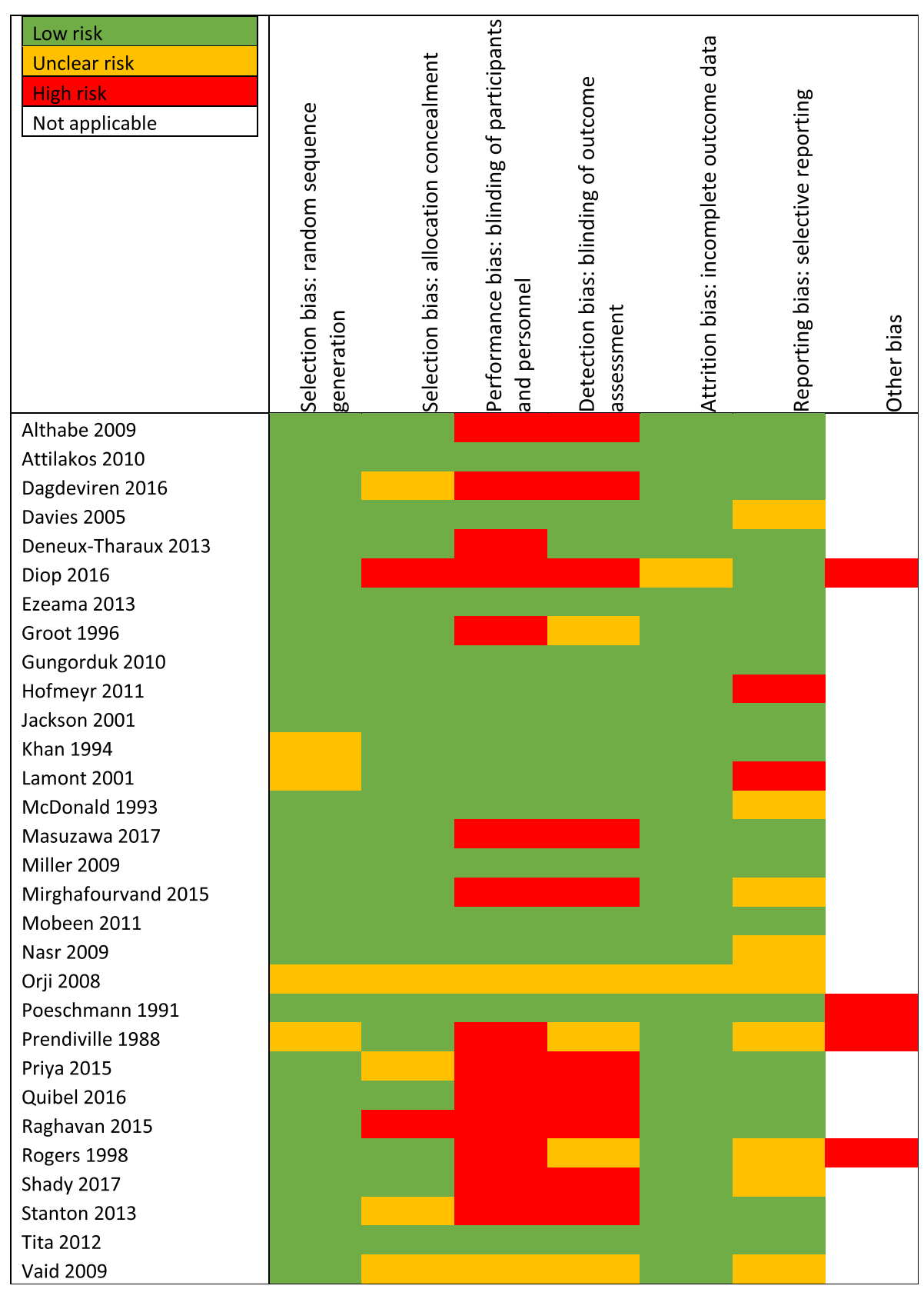

Fig. 3 Risk of bias based on authors' judgement for each included trial

3 included two trials and had a random effects pooled proportion of 0.14 ( $95 \% \mathrm{CI}=0.095$ to 0.18$)$, with medium heterogeneity $\left(p=0.07 ; I^{2}=69.6 \%\right)$ (Additional file 2 : Figure S3) [29, 42]. Grade 4 included 11 trials and had a random effects pooled proportion of $0.10(95 \% \mathrm{CI}=0.072$ to $0.14)$, with high heterogeneity $\left(p<0.0001 ; I^{2}=98.1 \%\right.$; $95 \%$ $\mathrm{CI}=97.8$ to $98.4 \%$ ) (Additional file 2: Figure S4) $[9,10,14$, $15,20,23,25,27,31,32,39]$. There were no trials included in grade 5 for minor PPH.

The pooled proportion across all grades for minor $\mathrm{PPH}$ was $0.11(95 \% \mathrm{CI}=0.086$ to 0.13$)$ and there was high heterogeneity across the grades $\left(p<0.0001 ; I^{2}=\right.$ 96.1\%; $95 \% \mathrm{CI}=93.4$ to $97.4 \%$ ) (Fig. 4). KruskalWallis analysis showed no statistically significant difference in minor $\mathrm{PPH}$ rates between the different allocated grades $(\mathrm{T}=0.92, p=0.82)$, and no significant difference with an all pairwise comparison of the individual grades.

\section{Proportion analysis for major PPH grades}

Overall, there were 21 trials reporting results for the proportion of participants with major PPH. Grade 1 


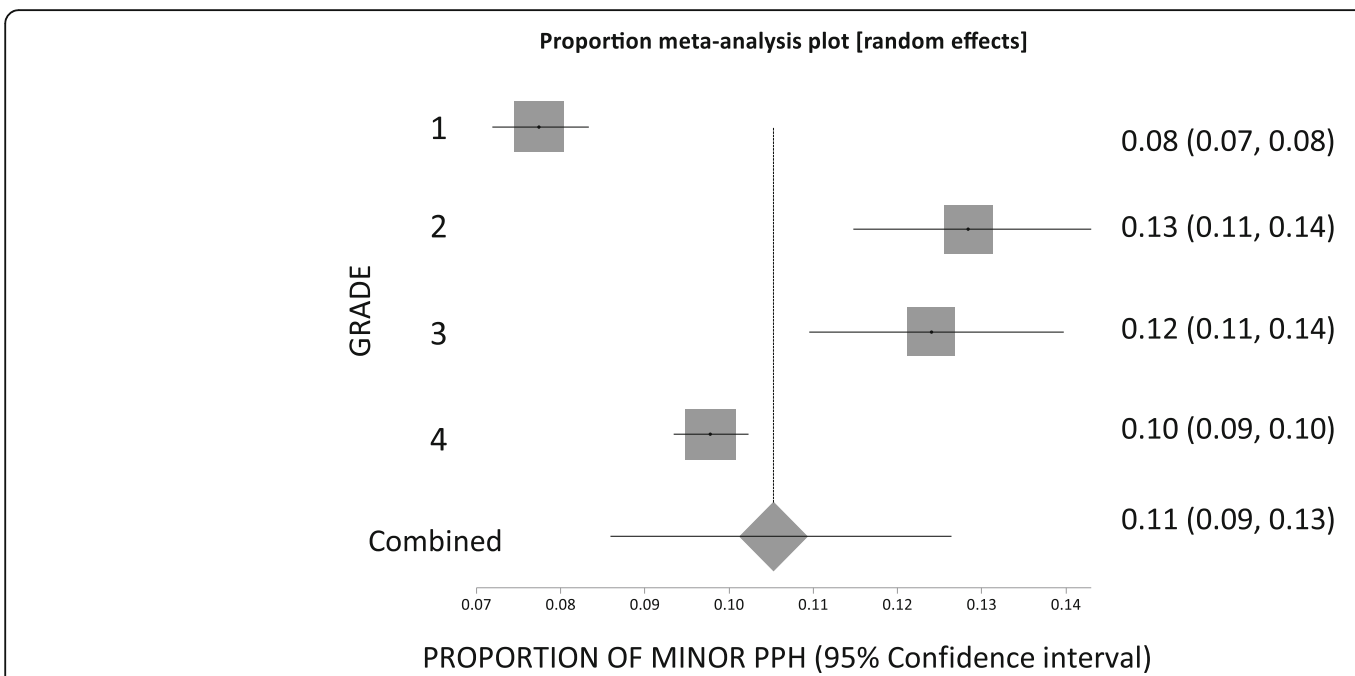

Fig. 4 Proportion meta-analysis box plot for overall minor postpartum haemorrhage (PPH) data from graded trials on prophylactic PPH interventions. There is no significant difference in the proportion of PPH across the minor PPH grades (Kruskal-Wallis: T $=0.92, p=0.82$ ). PPH - postpartum haemorrhage

included six trials and had a random effects pooled proportion of $0.033(95 \% \mathrm{CI}=0.011$ to 0.066$)$, with high heterogeneity across the trials $\left(p<0.0001 ; I^{2}=\right.$ 93.8\%; $95 \% \mathrm{CI}=89.8$ to $95.8 \%$ ) (Additional file 3: Figure S1) [12, 13, 18, 26, 38, 44]. Grade 2 included three trials and had a random pooled proportion of 0.033 (95\% CI 0.012 to 0.063 ), with high heterogeneity $\left(p=0.004 ; I^{2}=81.9 \% ; 95 \% \mathrm{CI}=0\right.$ to $92.3 \%$ ) (Additional file 3: Figure S2) $[16,35,41]$. Grade 3 included one trial with a proportion of $0.020(95 \%$ $\mathrm{CI}=0.014$ to 0.027) (Additional file 3: Figure S3) [42]. Grade 4 included 10 trials and had a random effects pooled proportion of 0.035 ( $95 \% \mathrm{CI}=0.015$ to 0.064$)$, with high heterogeneity $\left(p<0.0001 ; I^{2}=98.5 \% ; 95 \%\right.$ $\mathrm{CI}=98.3$ to $98.8 \%$ ) (Additional file 3: Figure S4) [9$11,14,15,20,25,31,32,39]$. Grade 5 included one trial with a proportion of $0.049(95 \% \mathrm{CI}=0.030$ to 0.073) (Additional file 3: Figure S5) [46].

The pooled proportion across all grades for major $\mathrm{PPH}$ was $0.030(95 \% \mathrm{CI}=0.022$ to 0.041$)$ with high heterogeneity across the grades $\left(\mathrm{p}<0.0001 ; I^{2}=90.8 \%\right.$; 95\% CI $=81$ to $94.4 \%$ ) (Fig. 5). Kruskal-Wallis analysis showed that there is no statistically significant difference in major $\mathrm{PPH}$ rates between the different grades ( $\mathrm{T}=0.91, p=0.92)$, and no significant difference with an all pairwise comparison of the individual grades.

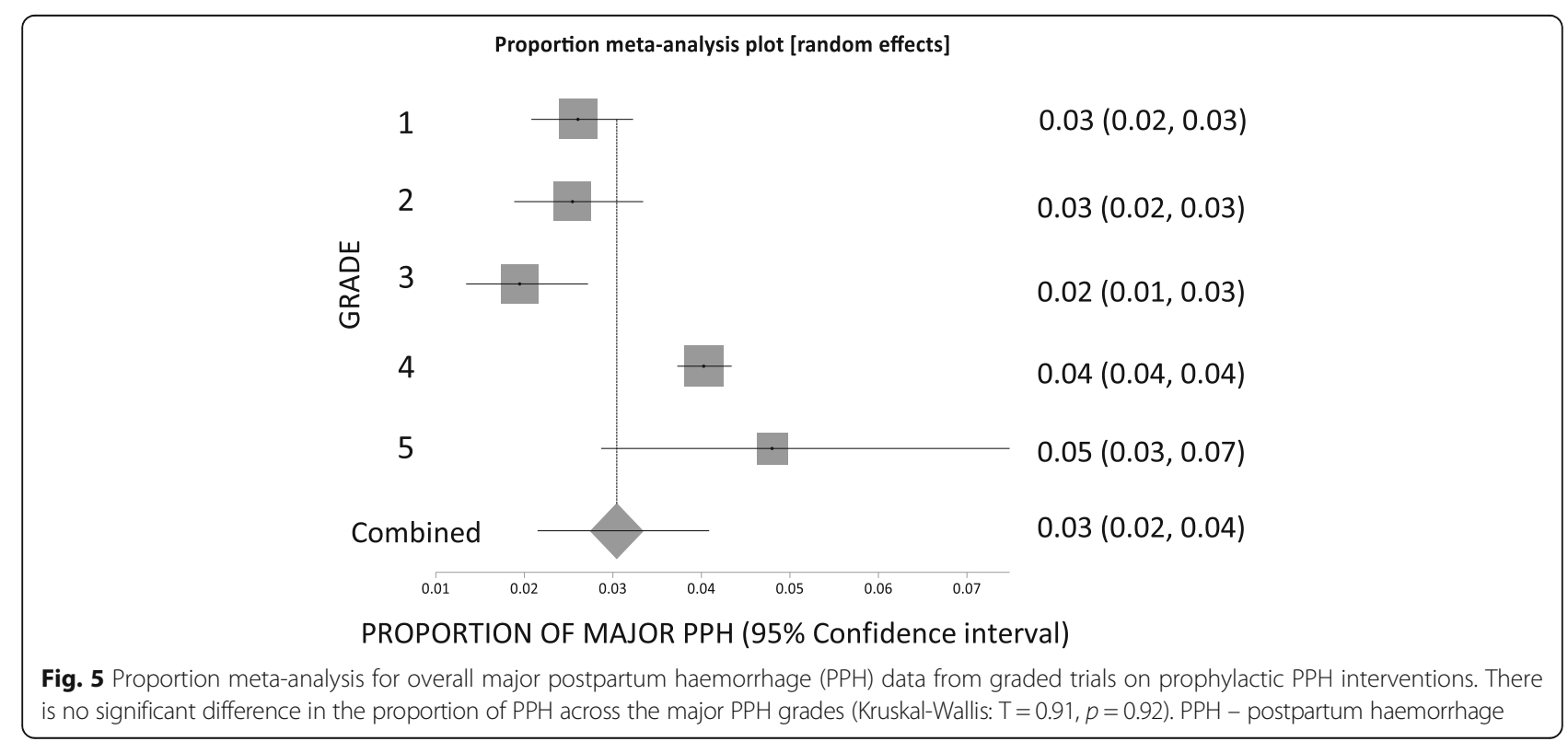




\section{Secondary outcomes}

\section{Methods comparison for minor PPH}

Seven trials for minor PPH collected blood loss data based on an estimated volume (median rate $=0.12$ ), whereas, 21 trials used a measurement of blood loss (median rate $=0.10$ ) (Fig. 6a). Measurement of blood loss included gravimetric measurement, BRASS-V drape collection, haemoglobin or haematocrit measurement and the traditional measurement of weighing blood-soaked items. Overall, there was no significant difference in the rates of minor $\mathrm{PPH}$ between the methods (Mann-Whitney $\mathrm{U}=67, \quad \mathrm{p} \quad$ (two-tailed) $=$ 0.75). All trials within grade 1 used a measurement to determine minor PPH (median rate $=0.061$ ). There was no significant difference in the rates of minor $\mathrm{PPH}$ between measured $(n=3$; median rate $=0.12)$ or estimated $(n=1$; median rate $=0.12)$ methods for grade 2 trials (Mann-Whitney $\mathrm{U}=2$, $\mathrm{p}$ (two-tailed) > 0.99). Grade 3 contained two trials, one used a measurement (median rate $=0.17$ ) and one used an estimate of blood loss (median rate $=0.12$ ). There was no significant difference in the rates of minor $\mathrm{PPH}$ between measured $(n=6$, median rate $=0.092)$ and estimated blood loss $(n=5$, median rate $=0.086)$ for grade 4 trials $($ Mann-Whitney $\mathrm{U}=12$, $\mathrm{p}($ two-tailed $)=$ $0.66)$.

\section{Methods comparison for major PPH}

For major PPH data, five trials reported data based on estimated blood loss (median rate $=0.024$ ) and 16 trials reported data using a measurement (median rate $=$ 0.025). There was no significant difference between the

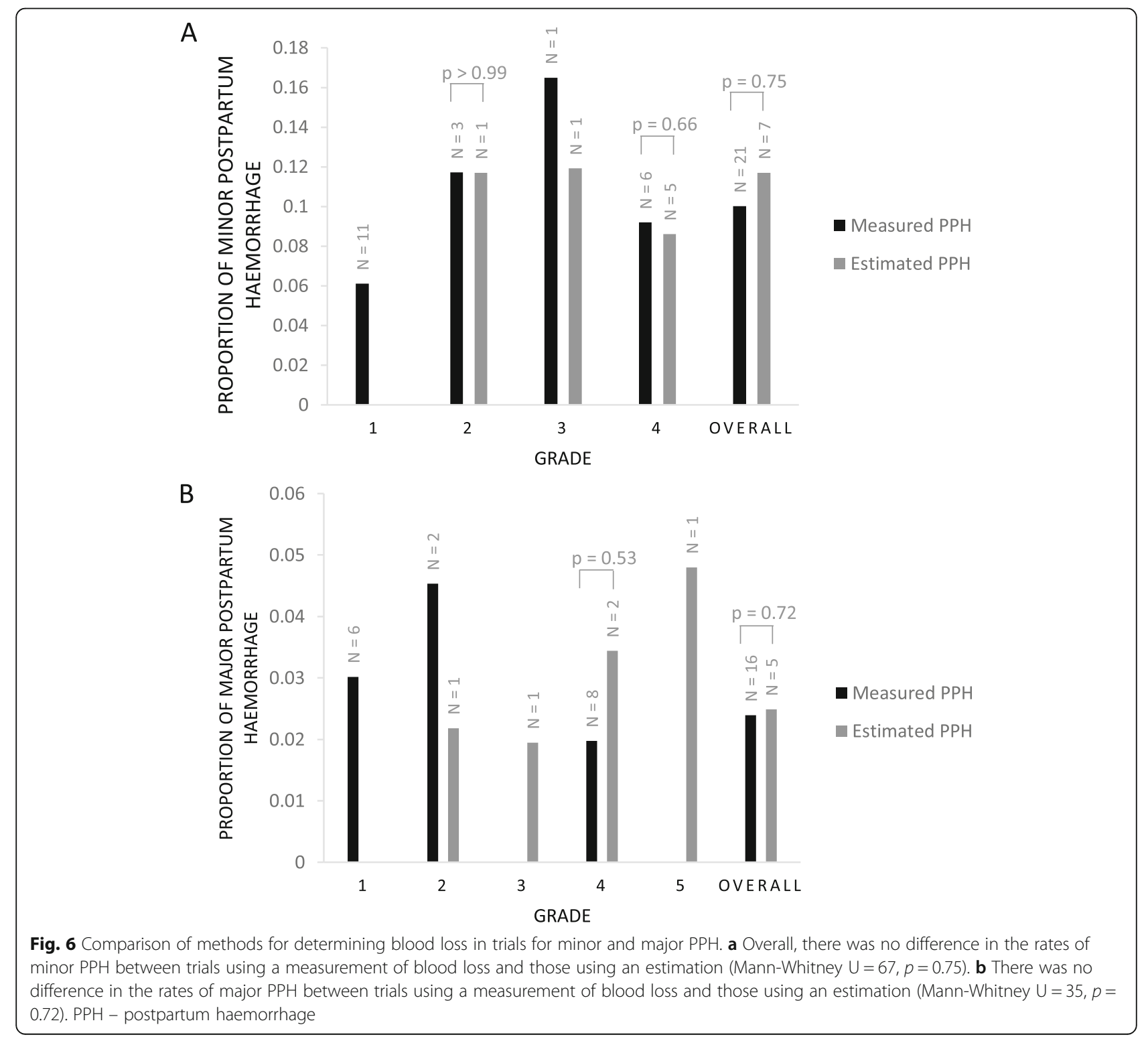


methods of determining the rate of PPH (Mann-Whitney $\mathrm{U}=35$, p (two-tailed) $=0.72$ ) (Fig. 6b). All six trials within grade 1 used a measurement of blood loss $(n=6$; median rate $=0.030$ ). Within grade 2 , two trials used a measurement (median rate $=0.045$ ) and one trial used an estimation (median rate $=0.022$ ). There was one trial in grade 3 which used an estimate to determine $\mathrm{PPH}$ rate (median rate $=0.019$ ). In grade 4 , there was no significant difference between the measured $(n=8$; median rate $=0.020)$ and estimated $(n=2$; median rate $=0.034)$ groups for the rate of major PPH (Mann-Whitney $U=5$, p $($ two tailed $)=0.53)$. Grade 5 contained one trial which used a method of estimation to determine the rate of PPH (median rate $=0.048)$.

\section{Post-hoc analysis}

Rate of PPH vs. \% operative births

Based on the results of post hoc analysis, the percentage of operative births in a study and the rate of minor $\mathrm{PPH}$ are significantly correlated (Spearman $r=0.32$ ) (Fig. 7a). However, there is no correlation between the percentage of operative births and the rate of major PPH (Spearman $r=0.098, \mathrm{p}($ two-tailed $)=0.34)($ Fig. $7 \mathrm{~b})$.

\section{Discussion}

This review compares PPH rates in trials of prophylaxis according to the participant inclusion criteria. Best practice recommendations for prophylaxis are based mainly on the evidence from RCTs, which largely only include
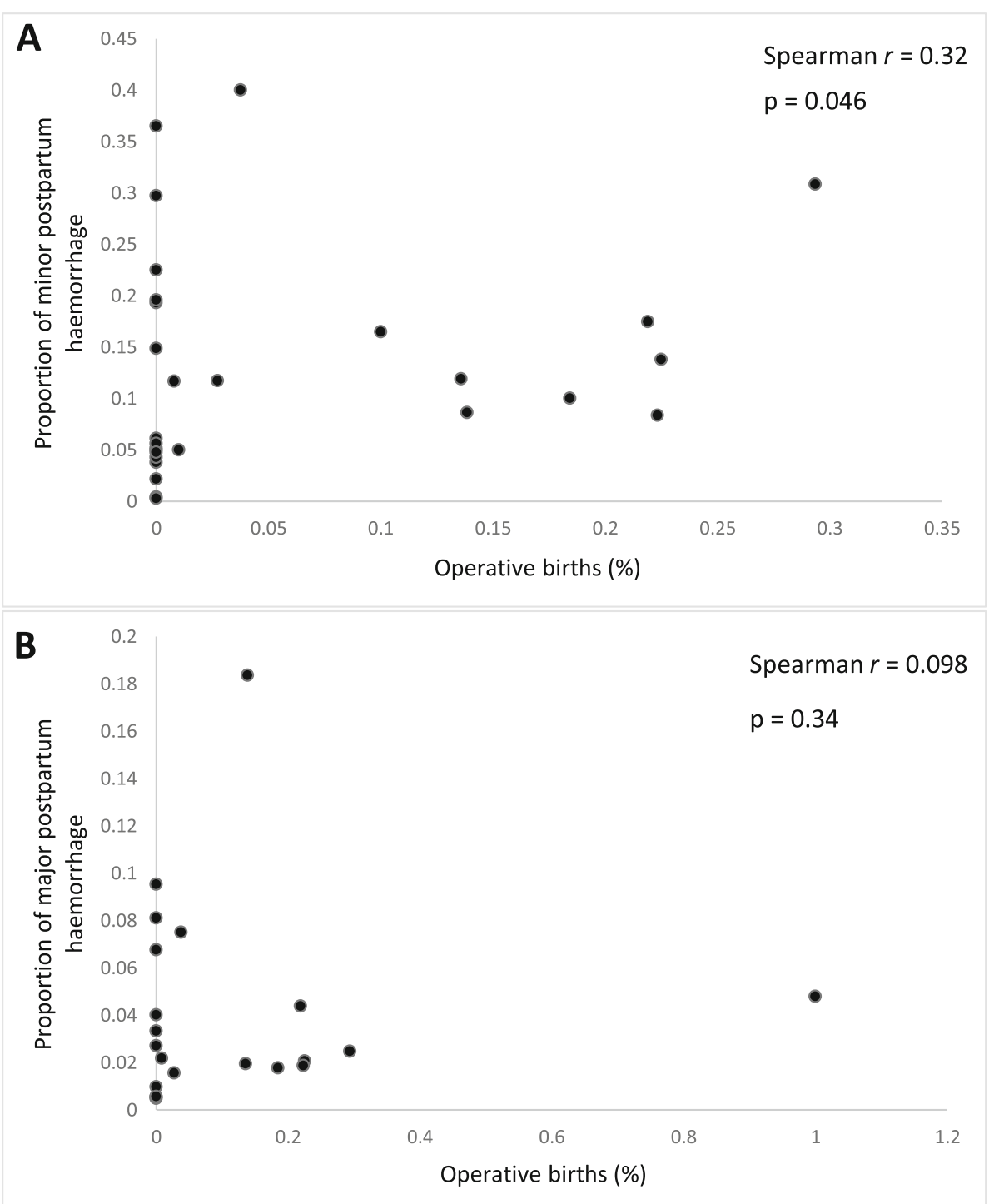

Fig. 7 Post hoc analysis of postpartum haemorrhage (PPH) vs. the percentage of operative births (operative vaginal and caesarean section) a) The rate of minor PPH significantly correlates with the percentage of operative births (Spearman rho $=0.32, p=0.046$ ). $\mathbf{b}$ The rate of major PPH did not correlate with the percentage of operative births (Spearman rho $=0.098, p=0.34$ ). $\mathrm{PPH}$ - postpartum haemorrhage 
low risk women who have, by definition, lower rates of haemorrhage. Trials focussing on PPH tend not to include women with more complex births, and therefore, current guidance may not address the target population $[4,48,49]$. Bais et al. suggest that the high PPH rate in their study could be due to their inclusion of high risk women, indicating inclusion criteria impacts reported trial rate [48]. The rates observed in trials of intervention often do not correlate with the WHO estimates of global prevalence. Weeks and Nielson argue that this is the result of widespread inclusion bias towards low risk women in current literature [4].

In this review, there was a disproportionate number of trials which only included low risk women with 39\% (11/ 30) in grade 1, the lowest risk category. Despite this, no differences in minor or major PPH rates were identified between grades, suggesting the exclusion of high risk births from trials does not influence the overall trial rate of $\mathrm{PPH}$. The lack of relationship between trial grade and overall rate could be due the effectiveness of interventions in all women, regardless of risk profile. This could imply that interventions have little or no effect on PPH rates in low risk women but result in lower PPH rates for trials including higher risk participants. If this were correct, it would explain the overall similar rates across all grades. However, this is not supported by $70 \%(21 / 30)$ of included trials reporting non-significant results for their intervention.

Commonly used uterotonics are based on evidence from low risk births which is then generalised to all women [4]. There is little evidence to describe their relationship with bleeding in complex births. Post-hoc analysis on the relationship of $\mathrm{PPH}$ with operative births (operative vaginal and caesarean section) identified significant correlation with minor, but nor major, $\mathrm{PPH}$ (Spearman $r=0.32, p=0.046$ v. Spearman $r=0.098, p=$ $0.34)$. Method of birth could have more influence on $\mathrm{PPH}$ rate than antenatal risk factors. In this review, a significant correlation was only found with minor PPH. However, this observed correlation is consistent with data from the Liverpool Women's Hospital, which shows that operative births disproportionately contribute to the incidence of haemorrhages $>2000 \mathrm{ml}$ [4]. In 2009-2013, operative births comprised $39.1 \%$ of births but $71.6 \%$ of PPH cases. The impact of operative births on PPH rates was also observed in a Scottish study where emergency C sections accounted for $41 \%$ of haemorrhages $\geq 2500 \mathrm{ml}$ but only $15 \%$ of total births in Scotland [50]. Despite evidence that women undergoing operative births are at higher risk of haemorrhage, they are often excluded from trial participation. In this review, over half (56.7\%) of trials excluded all operative births entirely. There needs to be more weight given to trials which include women with complex births as they are most in need of effective interventions [4].
The impact of visual estimation over objective measurement has been widely described $[6,51-53]$. This review did not identify a difference in PPH rates between studies that used estimation and measurement, contrary to many reports of inaccuracies with visual estimation in another review [6]. However, this current review defined measurement as any attempt at objectifying blood loss. This is not concordant with other trials and reviews which consider the traditional method as an estimation, where the loss is calculated from visual estimation and measurement of blood in drainage bottles and gauze [51]. This difference in definition could also explain the unexpectedly low number of trials using estimation $(25 \%$ of minor and $24 \%$ of major PPH).

\section{Limitations}

There was considerable heterogeneity across trials in all grades, for both minor and major $\mathrm{PPH}$, with $I^{2}$ ranging from 69.6 to $99.1 \%$. This suggests that there may be other factors other than antenatal risk factors and method of birth which would explain the differences in $\mathrm{PPH}$ rates in trials of prophylaxis. It would have been useful to identify predictors of rate through multiple regression; however, this review was limited by the inadequately sized data set. The small data set also prevented analysis of both minor and major PPH across all five grades. There was only one included trial in grade $\mathbf{5}$, which reported data for PPH $>1000 \mathrm{ml}$ only. Pooling of data from both arms of the trials is justified as $70 \%$ of trials showed no difference in rates. However, an alternative that could be explored is the use of data from the control arm only. As discussed, another limitation of this review was the definition of estimated and measured blood loss, which is inconsistent with other literature, resulting in only a small number of trials being identified as using estimation.

\section{What is already known on this topic}

Postpartum haemorrhage remains a leading cause of maternal death.

There is widespread inclusion bias towards low risk women in trials of intervention.

Operative births contribute to a large number of $\mathrm{PPH}$ incidents.

\section{What this study adds}

There is a disproportionate number of studies focussing only on low risk women and births.

Grading trials using antenatal risk factors and method of birth does not explain the variance in PPH rates.

Method of birth could be a more important predictor of $\mathrm{PPH}$ rate and hence, more weight should be given to studies focussing on complex births. 


\section{Conclusion}

This review showed that antenatal risk factors may not be a significant contributor to the variance in trial rates between studies, but the method of birth could have more impact. Operative vaginal may be an important contributor to PPH but women who give birth this way are often excluded from participating in trials and data supporting interventions in this population is therefore lacking. More focus on these women when conducting trials of intervention would be more appropriate to ensure that current recommendations for complex births are formed using a relevant evidence base.

\section{Supplementary information}

Supplementary information accompanies this paper at https://doi.org/10. 1186/s12884-020-2719-3.

Additional file 1. Risk of bias assessment for each of the included trials in detail with author judgment and support for this judgement.

Additional file 2. Proportion meta-analysis box plots for the individual grades for minor postpartum haemorrhage.

Additional file 3. Proportion meta-analysis box plots for the individual grades for major postpartum haemorrhage.

Additional file 4. Table of trials included in "A systematic review of postpartum haemorrhage (PPH) rates in randomized trials of PPH prophylactic interventions to examine the effect of underlying participant PPH risk".

\section{Abbreviations}

CENTRAL: Cochrane Central Register of Controlled Trials; Cl: Confidence interval; NICE: National Institute of Clinical Excellence; PPH: Postpartum haemorrhage; PRISMA: Preferred Reporting Items for Systematic Reviews and Meta-Analysis; RCOG: Royal College of Obstetricians and Gynaecologists; RCT: Randomised controlled trial; WHO: World Health Organisation

\section{Acknowledgements}

We would like to thank Dr. Steven Lane (Department of Biostatistics, University of Liverpool, Liverpool, UK) for providing expertise that assisted in this research and for his valuable comments on the manuscript.

\section{Authors' contributions}

Concept: LH and AW. Methodology: LH and AW. Data collection: LH. Formal analysis: LH. Supervision: AW. Writing of the original draft: LH. Review and editing: LH and AW. All authors have read and approved the manuscript.

\section{Funding}

There was no external funding source.

\section{Availability of data and materials}

All relevant data are given within the manuscript and the supplementary files (Additional file 4 table of trials included in this review).

\section{Ethics approval and consent to participate}

Not applicable.

\section{Consent for publication}

Not applicable.

\section{Competing interests}

The authors declare that they have no competing interests.
Received: 12 October 2018 Accepted: 3 January 2020

Published online: 13 February 2020

\section{References}

1. Say L, Chou D, Gemmill A, Tuncalp O, Moller AB, Daniels J, et al. Global causes of maternal death: a WHO systematic analysis. Lancet Glob Health. 2014:2(6):323-33.

2. Mavrides EAS, Chandraharan E, Collins P, Green L, Hunt BJ, Riris S, Thomson AJ. On behalf of the Royal College of Obstetricians and Gynaecologists Prevention and management of postpartum haemorrhage. BJOG Int J Obstet Gynaecol. 2016;124:e106-e49.

3. NICE. Intrapartum Care: Care of Healthy Women and their Babies during Childbirth. NICE. Clinical Guideline 190. London; 2014.

4. Weeks A, Neilson J. Rethinking our approach to postpartum haemorrhage and uterotonics. BMJ (Online). 2015;351.

5. Green L, Knight M, Seeney FM, Hopkinson C, Collins PW, Collis RE, et al. The epidemiology and outcomes of women with postpartum haemorrhage requiring massive transfusion with eight or more units of red cells: a national cross-sectional study. BJOG Int J Obstet Gynaecol. 2016;123(13): 2164-70.

6. Hancock A, Weeks AD, Lavender DT. Is accurate and reliable blood loss estimation the 'crucial step' in early detection of postpartum haemorrhage: an integrative review of the literature. BMC Pregnancy Childbirth. 2015:15:230

7. Higgins J, Green S, (editors). Cochrane Handbook for Systematic Reviews of Interventions. The Cochrane Collaboration 2011;Version 5.1.0 [updated March 2011].

8. de Haas S, Ghossein-Doha C, van Kuijk SM, van Drongelen J, Spaanderman ME. Physiological adaptation of maternal plasma volume during pregnancy: a systematic review and meta-analysis. Ultrasound Obstet Gynecol. 2017; 49(2):177-87.

9. Jackson KW Jr, Allbert JR, Schemmer GK, Elliot M, Humphrey A, Taylor J. A randomized controlled trial comparing oxytocin administration before and after placental delivery in the prevention of postpartum hemorrhage. Am J Obstet Gynecol. 2001;185(4):873-7.

10. Davies GA, Tessier JL, Woodman MC, Lipson A, Hahn PM. Maternal hemodynamics after oxytocin bolus compared with infusion in the third stage of labor: a randomized controlled trial. Obstet Gynecol. 2005;105(2): 294-9.

11. Diop A, Daff B, Sow M, Blum J, Diagne M, Sloan NL, et al. Oxytocin via Uniject (a prefilled single-use injection) versus oral misoprostol for prevention of postpartum haemorrhage at the community level: a clusterrandomised controlled trial. Lancet Glob Health. 2016:4(1):e37-44.

12. Güngördük K, Asicioglu $O$, Besimoglu B, Güngördük $O C$, Yildirm G, Ark $C$, et al. Using Intraumbilical vein injection of oxytocin in routine practice with active Management of the Third Stage of labor: a randomized controlled trial. Obstet Gynecol. 2010;116(3):619-24.

13. Hofmeyr GJ, Fawole B, Mugerwa K, Godi NP, Blignaut Q, Mangesi L, et al. Administration of $400 \mu \mathrm{g}$ of misoprostol to augment routine active management of the third stage of labor. Int J Gynaecol Obstet. 2011;112(2): 98-102.

14. Khan GQ, John IS, Chan T, Wani S, Hughes AO, Stirrat GM. Abu Dhabi third stage trial: oxytocin versus Syntometrine in the active management of the third stage of labour. Eur J Obstet Gynecol Reprod Biol. 1995;58(2):147-51.

15. Lamont RF, Morgan DJ, Logue M, Gordon H. A prospective randomised trial to compare the efficacy and safety of hemabate and syntometrine for the prevention of primary postpartum haemorrhage. Prostaglandins Other Lipid Mediat. 2001;66(3):203-10.

16. Masuzawa Y, Kataoka Y, Nakamura S, Yaju Y. Cooling the lower abdomen to reduce postpartum blood loss: a randomized controlled trial. PLoS One. 2017:12(10):e0186365

17. Miller S, Tudor C, Thorsten V. Nyima, Kalyang, Sonam, et al. Randomized double masked trial of Zhi Byed 11, a Tibetan traditional medicine, versus misoprostol to prevent postpartum hemorrhage in Lhasa, Tibet. J Midwifery Womens Health. 2009:54(2):133-41.e1.

18. Mirghafourvand M, Mohammad-Alizadeh S, Abbasalizadeh F, Shirdel M. The effect of prophylactic intravenous tranexamic acid on blood loss after vaginal delivery in women at low risk of postpartum haemorrhage: a double-blind randomised controlled trial. Aust N Z J Obstet Gynaecol. 2015; 55(1):53-8. 
19. Priya GP, Veena P, Chaturvedula L, Subitha L. A randomized controlled trial of sublingual misoprostol and intramuscular oxytocin for prevention of postpartum hemorrhage. Arch Gynecol Obstet. 2015;292(6):1231-7.

20. Quibel T, Ghout I, Goffinet F, Salomon LJ, Fort J, Javoise S, et al. Active Management of the Third Stage of labor with a combination of oxytocin and misoprostol to prevent postpartum hemorrhage: a randomized controlled trial. Obstet Gynecol. 2016;128(4):805-11.

21. Raghavan S, Geller S, Miller S, Goudar S, Anger H, Yadavannavar M, et al. Misoprostol for primary versus secondary prevention of postpartum haemorrhage: a cluster-randomised non-inferiority community trial. BJOG Int J Obstet Gynaecol. 2016;123(1):120-7.

22. Shady NW, Sallam HF, Elsayed AH, Abdelkader AM, Ali SS, Alanwar A, et al. The effect of prophylactic oral tranexamic acid plus buccal misoprostol on blood loss after vaginal delivery: a randomized controlled trial. J Matern Fetal Neonatal Med. 2017:1-7.

23. Tita AT, Szychowski JM, Rouse DJ, Bean CM, Chapman V, Nothern A, et al. Higher-dose oxytocin and hemorrhage after vaginal delivery: a randomized controlled trial. Obstet Gynecol. 2012;119(2 Pt 1):293-300.

24. Ezeama CO, Eleje GU, Ezeama NN, Igwegbe AO, Ikechebelu JI, Ugboaja JO, et al. A comparison of prophylactic intramuscular ergometrine and oxytocin for women in the third stage of labor. Int J Gynaecol Obstet. 2014;124(1): 67-71.

25. McDonald SJ, Prendiville WJ, Blair E. Randomised controlled trial of oxytocin alone versus oxytocin and ergometrine in active management of third stage of labour. Br Med J. 1993;307(6913):1167-71.

26. Mobeen N, Durocher J, Zuberi N, Jahan N, Blum J, Wasim S, et al. Administration of misoprostol by trained traditional birth attendants to prevent postpartum haemorrhage in homebirths in Pakistan: a randomised placebo-controlled trial. BJOG Int J Obstet Gynaecol. 2011;118(3):353-61.

27. Nasr A, Shahin AY, Elsamman AM, Zakherah MS, Shaaban OM. Rectal misoprostol versus intravenous oxytocin for prevention of postpartum hemorrhage. Int J Gynaecol Obstet. 2009;105(3):244-7.

28. Orji E, Agwu F, Loto O, Olaleye O. A randomized comparative study of prophylactic oxytocin versus ergometrine in the third stage of labor. Int J Gynaecol Obstet. 2008;101(2):129-32.

29. Vaid A, Dadhwal V, Mittal S, Deka D, Misra R, Sharma JB, et al. A randomized controlled trial of prophylactic sublingual misoprostol versus intramuscular methyl-ergometrine versus intramuscular 15-methyl PGF2alpha in active management of third stage of labor. Arch Gynecol Obstet. 2009;280(6):893-7.

30. Gallos ID, Papadopoulou A, Man R, Athanasopoulos N, Tobias A, Price MJ, et al. Uterotonic agents for preventing postpartum haemorrhage: a network meta-analysis. Cochrane Database Syst Rev 2018(12):Art No.: CD011689. DOI: https://doi.org/10.1002/14651858.CD011689.pub3.

31. Althabe F, Alemán A, Tomasso G, Gibbons L, Vitureira G, Belizán JM, et al. A pilot randomized controlled trial of controlled cord traction to reduce postpartum blood loss. Int J Gynaecol Obstet. 2009;107(1):4-7.

32. Deneux-Tharaux C, Sentilhes L, Maillard F, Closset E, Vardon D, Lepercq J, et al. Effect of routine controlled cord traction as part of the active management of the third stage of labour on postpartum haemorrhage: multicentre randomised controlled trial (TRACOR). Br Med J. 2013;346:f1541.

33. Hofmeyr GJ, Mshweshwe NT, Gülmezoglu AM. Controlled cord traction for the third stage of labour. Cochrane Database Syst Rev 2015(1):Art. No.: CD008020. DOl: https://doi.org/10.1002/14651858.CD008020.pub.

34. Oladapo OT, Okusanya BO, Abalos E. Intramuscular versus intravenous prophylactic oxytocin for the third stage of labour. Cochrane Database Syst Rev 2018(9):Art. No.: CD009332. DOI: https://doi.org/10.1002/14651858. CD009332.pub3.

35. Dagdeviren H, Cengiz H, Heydarova U, Caypinar SS, Kanawati A, Guven E, et al. Intramuscular versus intravenous prophylactic oxytocin for postpartum hemorrhage after vaginal delivery: a randomized controlled study. Arch Gynecol Obstet. 2016;294(5):911-6.

36. Soltani H, Hutchon DR, Poulose TA. Timing of prophylactic uterotonics for the third stage of labour after vaginal birth. Cochrane Database Syst Rev 2010(8):Art. No.: CD006173. DOl: https://doi.org/10.1002/14651858. CD006173.pub2

37. Westhoff G, Cotter AM, Tolosa JE. Prophylactic oxytocin for the third stage of labour to prevent postpartum haemorrhage. Cochrane Database Syst Rev 2013(10):Art. No.: CD001808. DOl: https://doi.org/10.1002/14651858. CD001808.pub2.
38. Poeschmann R, Doesburg W, Eskes T. A randomized comparison of oxytocin, sulprostone and placebo in the management of the third stage of labour. BJOG Int J Obstet Gynaecol. 1991;98(6):528-30.

39. Stanton CK, Newton S, Mullany LC, Cofie P, Tawiah Agyemang C, Adiibokah E, et al. Effect on postpartum hemorrhage of prophylactic oxytocin (10 IU) by injection by community health officers in Ghana: a community-based, Cluster-Randomized Trial. PLoS Med. 2013;10(10):e1001524.

40. Pantoja T, Abalos E, Chapman E, Vera C, Serrano VP. Oxytocin for preventing postpartum haemorrhage (PPH) in non-facility birth settings. Cochrane Database Syst Rev 2016(4):Art. No.: CD011491. DOl: https://doi.org/10.1002/ 14651858.CD011491.pub2.

41. Rogers J, Wood J, McCandlish R, Ayers S, Truesdale A, Elbourne D. Active versus expectant management of third stage of labour: the Hinchingbrooke randomised controlled trial. Lancet. 1998;351(9104):693-9.

42. Prendiville WJ, Harding JE, Elbourne DR, Stirrat GM. The Bristol third stage trial: active versus physiological management of third stage of labour. $\mathrm{Br}$ Med J. 1988;297(6659):1295.

43. Begley CM, Gyte GML, Devane D, McGuire W, Weeks A. Active versus expectant management for women in the third stage of labour. Cochrane Database Syst Rev 2015(3):Art No.: CD007412. DOl: https://doi.org/10.1002/ 14651858.CD007412.pub4.

44. de Groot AN, van Roosmalen J, van Dongen PW, Borm GF. A placebocontrolled trial of oral ergometrine to reduce postpartum hemorrhage. Acta Obstetrica et Gynecologica Scandanavica. 1996;75(5):464-8.

45. Liabsuetrakul T, Choobun T, Peeyananjarassri K, Islam QM. Prophylactic use of ergot alkaloids in the third stage of labour. Cochrane Database Syst Rev 2018(6):Art. No.: CD005456. DOI: https://doi.org/10.1002/14651858. CD005456.pub3.

46. Attilakos G, Psaroudakis D, Ash J, Buchanan R, Winter C, Donald F, et al. Carbetocin versus oxytocin for the prevention of postpartum haemorrhage following caesarean section: the results of a double-blind randomised trial. BJOG Int J Obstet Gynaecol. 2010;117(8):929-36.

47. Su LL, Chong YS, Samuel M. Carbetocin for preventing postpartum haemorrhage. Cochrane Database Syst Rev 2012(4):Art. No.: CD005457. DOI: https://doi.org/10.1002/14651858.CD005457.pub4.

48. Bais JMJ, Eskes M, Pel M, Bonsel GJ, Bleker OP. Postpartum haemorrhage in nulliparous women: incidence and risk factors in low and high risk women: a Dutch population-based cohort study on standard ( $\geq 500 \mathrm{ml}$ ) and severe ( $\geq 1000 \mathrm{ml}$ ) postpartum haemorrhage. Eur J Obstet Gynecol Reprod Biol. 2004;115(2):166-72.

49. Mousa HA, Blum J, Abou El Senoun G, Shakur H, Alfirevic Z. Treatment for primary postpartum haemorrhage. Cochrane Database Syst Rev 2014(2):Art. No.: CD003249. DOI: https://doi.org/10.1002/14651858.CD003249.pub3.

50. Brace $V$, Kernaghan D, Penney G. Learning from adverse clinical outcomes: major obstetric haemorrhage in Scotland, 2003-05. BJOG Int J Obstet Gynaecol. 2007;114(11):1388-96.

51. Larsson C, Saltvedt S, Wiklund I, Pahlen S, Andolf E. Estimation of blood loss after cesarean section and vaginal delivery has low validity with a tendency to exaggeration. Acta Obstet Gynecol Scand. 2006;85(12):1448-52.

52. Calvert C, Thomas SL, Ronsmans C, Wagner KS, Adler AJ, Filippi V. Identifying regional variation in the prevalence of postpartum haemorrhage: a systematic review and meta-analysis. PLoS One. 2012;7(7):e41114.

53. Knight M, Callaghan WM, Berg C, Alexander S, Bouvier-Colle M-H, Ford JB, et al. Trends in postpartum hemorrhage in high resource countries: a review and recommendations from the international postpartum hemorrhage collaborative group. BMC Pregnancy and Childbirth. 2009;9(1):55.

\section{Publisher's Note}

Springer Nature remains neutral with regard to jurisdictional claims in published maps and institutional affiliations. 